How young(er) adults with life-limiting conditions may best be supported in making relationships, sexual and reproductive choices?

The views of their carers, professional staff, family members and friends who support them?

Methodology Semi- structured Interviews are being conducted with young people over 16 years with Cystic Fibrosis and Duchenne Muscular Dystrophy, as well as the carers and professionals who support them. The data will be analysed using NVIVO software.

Results Pilot data and early findings from the main study will be addressed plus the ethical issues of undertaking sensitive research about sexuality with young adults with life-limiting conditions.

Conclusions These will be addressed in 2014 .

REFERENCE

1 Blackburn M.C. (2002) Sexuality and Disability: Butterworth-Heinemann, Elsevier Science.

\section{P 033 RELATIONSHIPS AND SEXUALITY IN YOUNG ADULTS WITH LIFE-LIMITING CONDITIONS IN THE UK}

Maddie Blackburn, Sarah Earle, Carol Komaromy. The Open University, Milton Keynes, England

\subsection{6/bmjspcare-2014-000654.74}

Background Until recently surviving into adulthood with a lifelimiting condition was rare, and as such, young(er) adults with life-limiting conditions are now a unique population about whom it is timely to explore their considerations about sexuality, relationships and reproduction. Young adults with chronic conditions diagnosed in childhood, especially those which are lifelimiting or life-threatening may well be less mature than their healthy peers( Beresford, 2013) but may still desire to experience an intimate relationship. The' emerging adult's' survival into adulthood is due to advancements in medicine and technology (Craig \& Lidstone, 2012). This research builds upon the first author's previous research into the sexuality of young adults with neural tube defects (Blackburn, 2002; Blackburn, 2008) and is the focus of her current PhD.

Aims The research is exploring:

The views and experiences of young(er) adults with life-limiting conditions about relationships, sex and reproduction? 